\title{
Electromechanical Coupled Vibration between Traction Motor and Bogie of High-Speed Train
}

\author{
Zhiqiang Zhang ${ }^{1, \text { a }}$, Xinying Zhao*2, b ${ }^{2}$ Xiangfei Li ${ }^{1}$, Fei Lin ${ }^{2}$, Zhongping Yang ${ }^{2}$ \\ ${ }^{1}$ CRRC Qingdao Sifang Co., Ltd., Qingdao, 266000, China \\ ${ }^{2}$ School of Electrical Engineering, Beijing Jiaotong University, Beijing, 100044, China \\ aemail: zzqiang@cqsf.com, bemail:14121518@bjtu.edu.cn
}

Keywords: Harmonic Torque; Electromechanical Coupled Vibration; Resonance Frequency

\begin{abstract}
In high-speed train, the harmonics generated in invertor due to control and nonlinear of switch may lead to the torque ripple in different frequency and amplitude. The driving device which consists of rotor, coupling, gear, shift and wheels of bogie has some resonance frequencies. When there are frequencies which are same or close to the resonance frequency of shifts in the torque pulsation, the shifts would be vibrated. First the paper analyzes the cause and influence of the torque pulsation. Then the author calculates the vibration frequencies of drive devices. Finally the author simulates the coupling system of driving motor and bogie driving device.
\end{abstract}

\section{Introduction}

High-speed train's traction drive system is an electromechanical coupling system, In the process of traction operation, traction motor produces torque to the wheels through driving devices, ultimately driving train moving at high speed. To ensure the reliability and absolute security of high-speed train, the traction force and torque should be output stably, otherwise the shaft vibration caused by motor torque ripple will affect the life of device and operation security of train.

Currently, there are many international reports about this, mainly about driving device especially for locomotive. References [1-3] studied on failure of mechanical part when electrical part is failure. References [4] analyzed vibration state in bogie-mounted traction system of locomotive. These papers all focus on torsional vibration just from the view of machinery. This paper mainly analyzes the forced vibration of the mechanical structure when excited by motor torque ripple.

\section{The Low-Frequency Harmonic Torque of Traction Motor}

Ultraharmonics in inverter usually caused by switching action, but switching devices are not ideal in reality, so there are severe distortions of current and low-frequency torque ripple which mainly caused by dead-time of switches[5].

(a)

Ideal voltage

(b) $i_{a}$

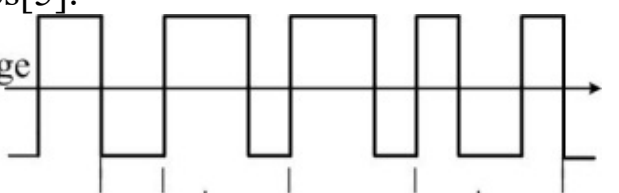

(c) Real voltage

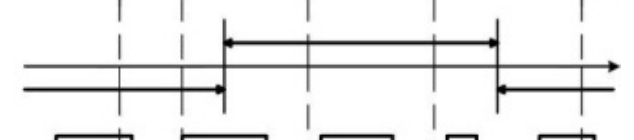

(d)

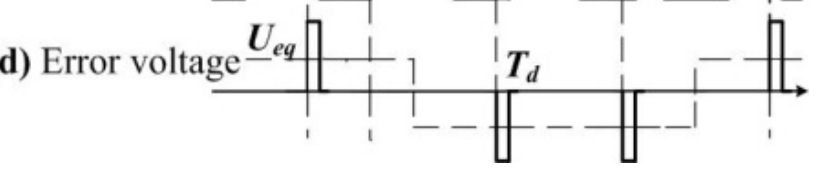

Fig.1. Waveform of output voltage affected by dead-time.

The error voltage pulse in Fig. 1(d) can be equivalent to a square-wave voltage $u_{e f}$, and its 
amplitude $U_{e q}$ is:

$U_{\mathrm{eq}}=f_{c} U_{d} T_{d}$

In the type: $f_{c}$ is carrier frequency, $T_{d}$ is dead-time.

$u_{e f}$ can be expressed by FFT:

$u_{e f}=\frac{4 U_{\mathrm{eq}}}{\pi}\left(\sin \omega t+\frac{1}{5} \sin 5 \omega t+\frac{1}{7} \sin 7 \omega t+\cdots \frac{1}{n} \sin n \omega t\right]$

In the type (2): $\omega$ is stator frequency, $n$ is odd number and not the multiple of 3 .

The simulation is based on the motor control model in CRH2A EMUs, the 5th current harmonic of different dead-time are shown in Fig.2.

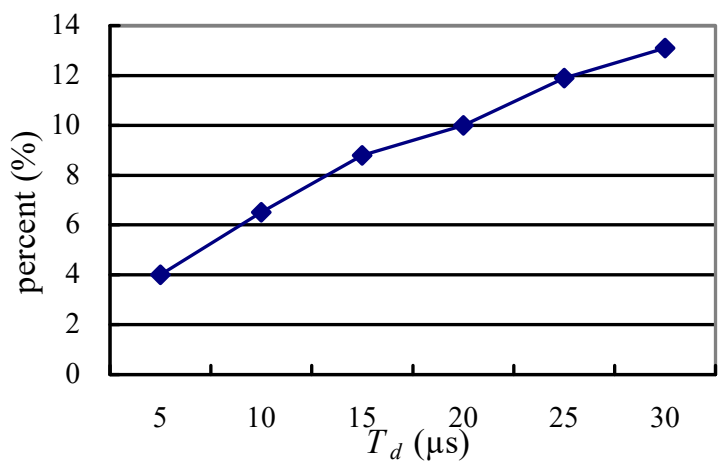

Fig.2. Percentage of 5 th harmonic on fundamental current

The 5th and 7th current harmonics will result low-frequency harmonic torque and the pulsation frequency is six times the stator fundamental frequency [6].

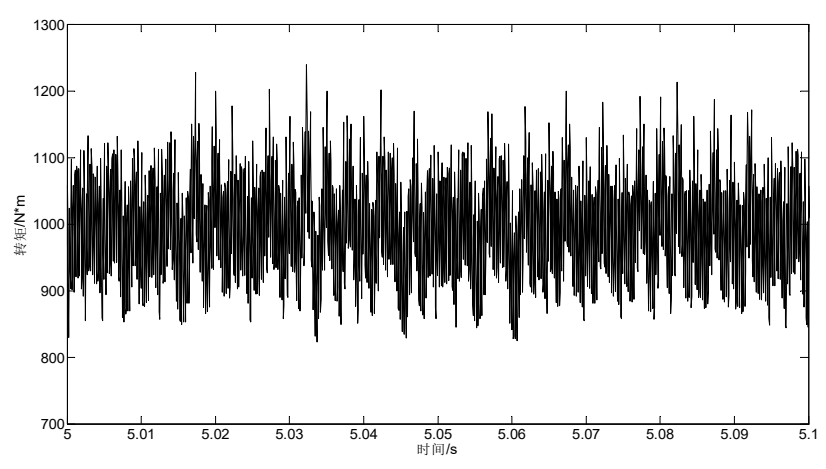

(a) dead-time is $0 \mu \mathrm{s}$

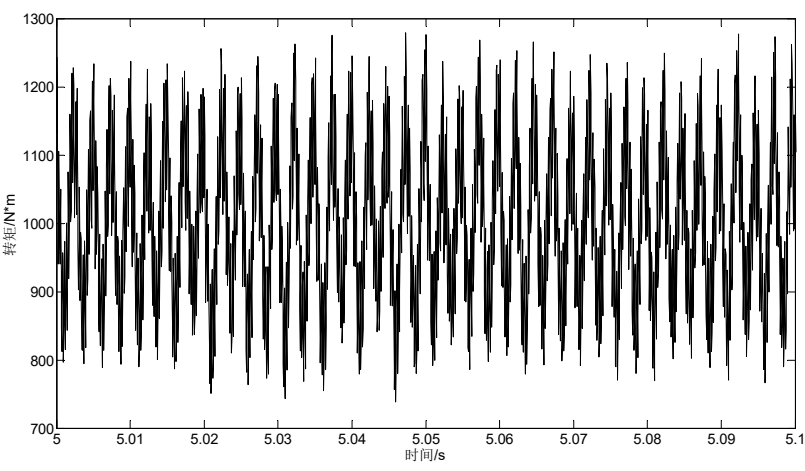

(b) dead-time is $15 \mu \mathrm{s}$

Fig.3. Torque pulsation waveforms

5th harmonic results in low frequency torque ripple and the pulsation frequency $(397.2 \mathrm{~Hz})$ is six times the stator fundamental frequency $(66.2 \mathrm{~Hz})$, and the peak-to-peak values of the torque pulsation increases from 280 N.m to 420 N.m.

\section{Mechanical Vibration of driving device}

To have a comprehensive consider about shaft vibration frequency, drive system is divided to 5 parts based on following assumptions [7]:

(1) Without regard to efficiency of powerdriven transmission and gap of drive system;

(2) Without regard to the elasticity of train axle, gear, gear shaft and so on;

(3) Drive, driving elements are seen as lumped mass. 


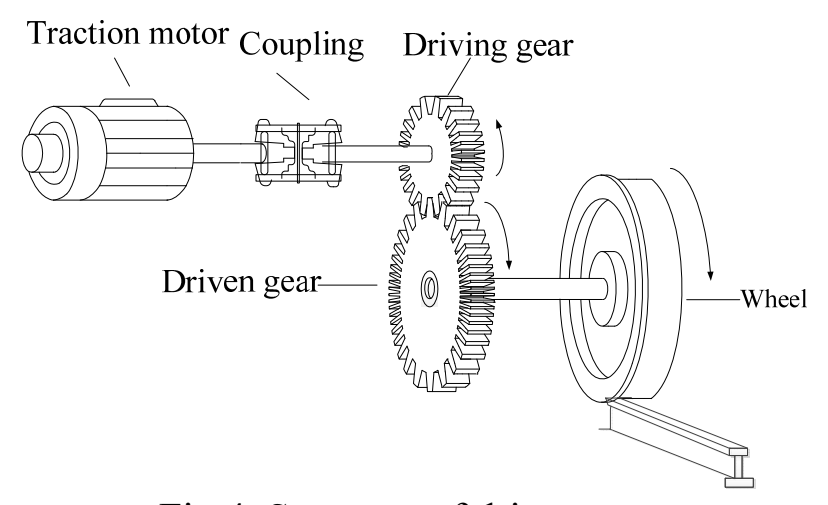

Fig.4. Structure of drive system

Lumped mass analysis model of driving system as shown in Fig. 5, drive devices are equivalent to disks that have inertia connected by 4 axles.

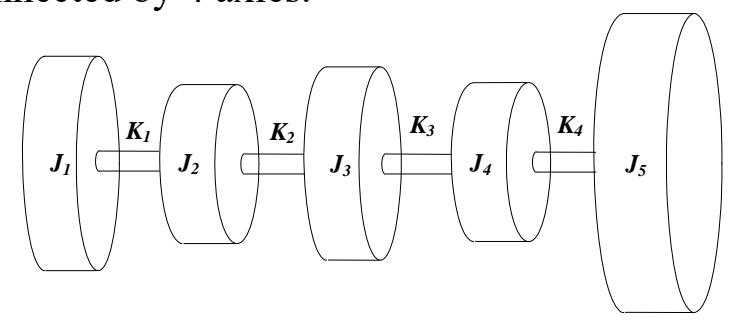

Fig.5. Lumped mass analysis model of drive system

In the type: $J_{i}$ is equivalent rotational inertia and $K_{i}$ is equivalent torsional rigidity.

The basis mechanics equation can be established according to the lumped mass model [8]:

$\boldsymbol{J} \ddot{\boldsymbol{\theta}}+\boldsymbol{K} \boldsymbol{\theta}=\mathbf{0}$

The characteristic root of equation (3) is:

$\theta_{i}=A_{i} \sin (\omega t+\varphi)$

Substitute into (3):

$\left(\boldsymbol{K}-\omega^{2} \boldsymbol{J}\right) \boldsymbol{A}=\mathbf{0}$

In the type: $A$ is column vector of amplitude, $\omega$ is shaft free vibration frequency.

$A$ must be satisfied to have non-zero solutions:

$\left|\boldsymbol{K}-\omega^{2} \boldsymbol{J}\right|=\mathbf{0}$

So we can get free vibration frequency according to parameters:

$\omega_{1}=51.13 \mathrm{rad} / \mathrm{s}$

$\omega_{2}=113.82 \mathrm{rad} / \mathrm{s}$

$\omega_{3}=173.35 \mathrm{rad} / \mathrm{s}$

$\omega_{4}=1322.70 \mathrm{rad} / \mathrm{s}$

The mechanical structure model of drive system is established by SimMechanics in Matlab, and then analyses the vibration frequency by simulation.

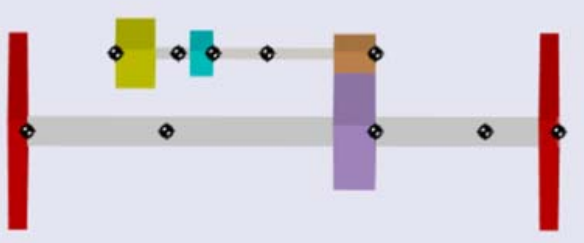

Fig.6. Simulation model in SimMechanics

Linearize the system and then draw bode plots of motor torque to rotation angle, angular velocity and angular acceleration of wheel considering damping factor, as shown in Fig.7 in turn. 


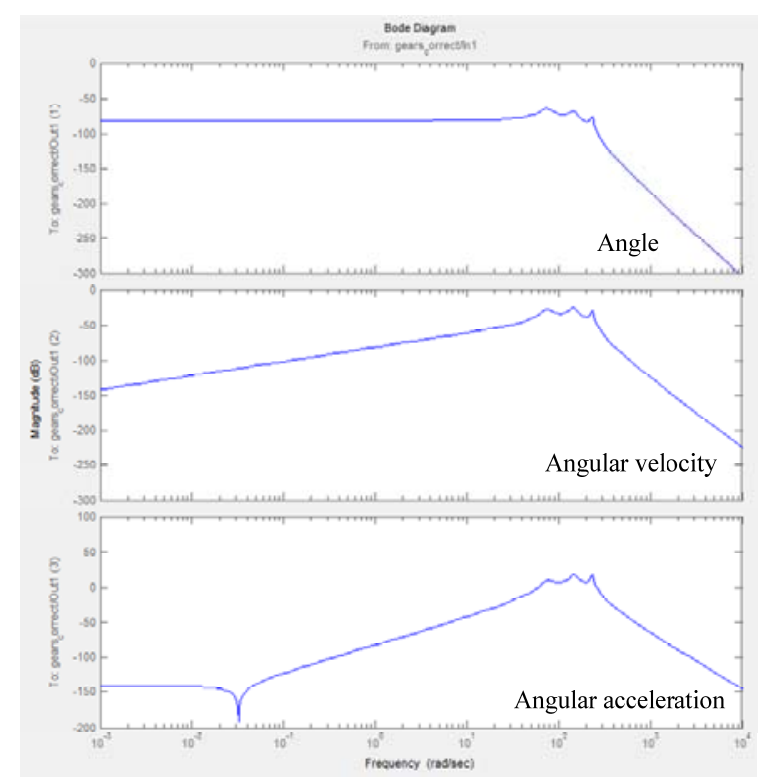

Fig.7. Damped amplitude-frequency characteristics

As it is clear from Fig. 7 that there are 3 resonance point considering system damping shown as Table.1:

Table.1 Resonant frequencies and peak gains of angular acceleration

\begin{tabular}{cccc}
\hline Number & Resonant frequencies/rad/s & peak gains $/ \mathrm{dB}$ & Resonant frequencies $/ \mathrm{Hz}$ \\
\hline$\omega_{1}$ & 72.5 & 8.65 & 11.54 \\
$\omega_{2}$ & 151 & 18.86 & 24.04 \\
$\omega_{3}$ & 233 & 15.87 & 37.10 \\
\hline
\end{tabular}

Damped vibration frequencies of drive system are increased compared with free vibration, and a free vibration frequency disappears when considering damping factor.

Resonant frequencies of rotation angle, angular velocity and angular acceleration of wheel are consistent, and the peak gains of angular acceleration are exceed $0 \mathrm{~dB}$, so the driving system will vibrate persistently if the system input contains the same frequency components like resonant frequencies.

\section{Shaft Torsional Vibration Considering Electromechanical Coupling}

The torque pulsation frequency of traction motor is six times the stator fundamental frequency and the resonance frequency of drive system are nearly $30 \mathrm{~Hz}$ according to the analysis and results above, the train runs at low speed this moment. In this chapter, take $\omega_{3}(37.1 \mathrm{~Hz})$ as an example to show shaft torsional vibration.

Resonant frequency $\omega_{3}=37.1 \mathrm{~Hz}$, frequency of motor torque pulsation is the same with $\omega_{3}$ when the frequency of motor stator is $6.183 \mathrm{~Hz}$, It can be calculated that corresponding running speed of train is about $7 \mathrm{~km} / \mathrm{h}$. So we can get the FFT of motor current when train runs at $7 \mathrm{~km} / \mathrm{h}$ by simulation as shown in Fig.8.

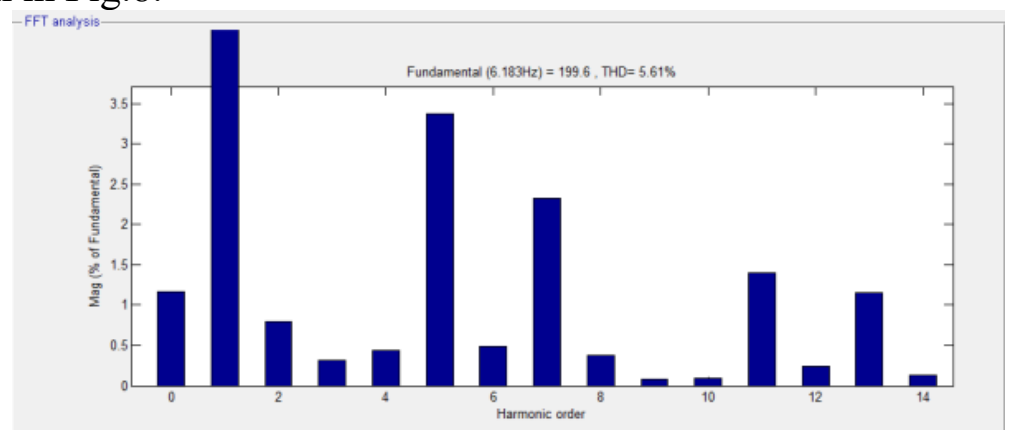

Fig.8. FFT of motor current

As it is clear from the simulation result in Fig.8, there are mainly 5th, 7th, 11th and 13th current 
harmonics.

The models of motor control and torsional vibration are connected, the joint simulation is realized, and then the vibration performance can be observed by angular acceleration of pinion. The simulation condition is: train accelerates from $0 \mathrm{~km} / \mathrm{h}$ to $7 \mathrm{~km} / \mathrm{h}$ in 2.5 seconds, and then runs at a constant speed of $7 \mathrm{~km} / \mathrm{h}$ after 2.5 seconds.
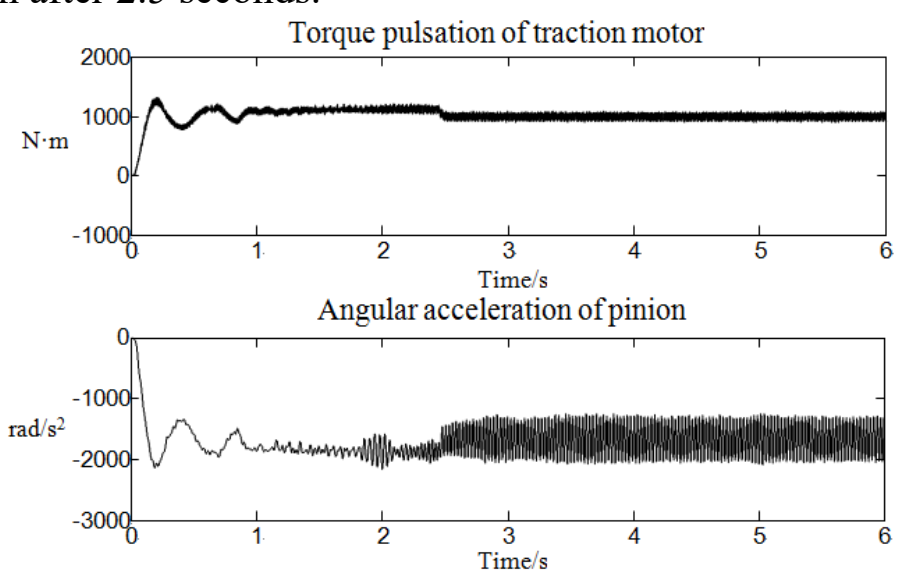

Fig.9. Comparison of torque pulsation and shaft torsional vibration

As it is shown in Fig. 9 that there are obvious low-frequency torque pulsations after 2.5 seconds, and the ripple frequency is $37 \mathrm{~Hz}$, which is six times the stator frequency $(6.183 \mathrm{~Hz})$.

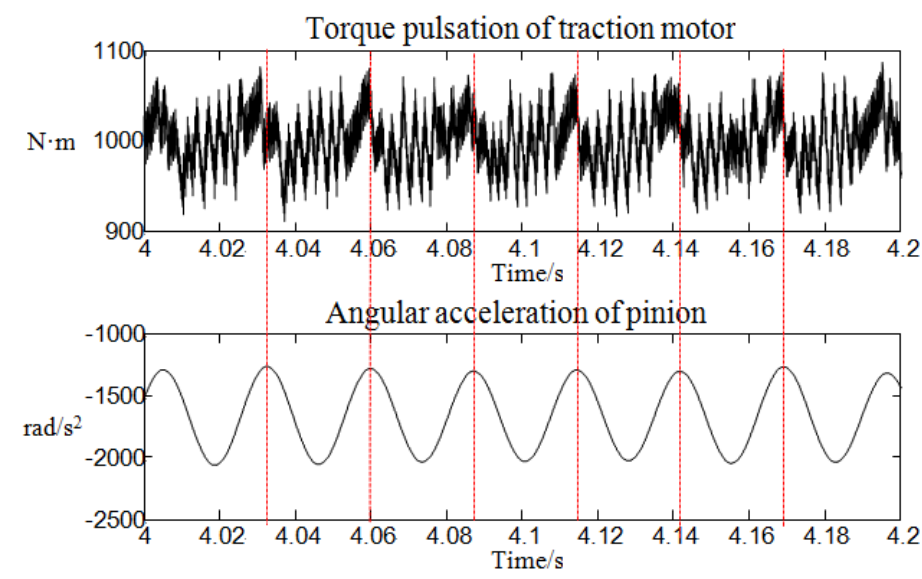

Fig.10. Partial enlarged views of torque pulsation and shaft torsional vibration

In the Fig.9 and Fig.10, the torsional vibration is weak during the accelerative state in 2.5 seconds, but the vibration amplitudes after 2.5 seconds increased by 4 times compared with the previous 2.5 seconds, and the vibration frequency is completely consistent with torque ripple frequency. So if train runs at the resonant speed, the shaft torsional vibration will be serious.

Observe torque pulsation and shaft torsional vibration between 1.7-2.2s as shown in Fig.11, the torque pulsation and shaft vibration aggravated between 1.85-2.05 seconds and then slowed down.
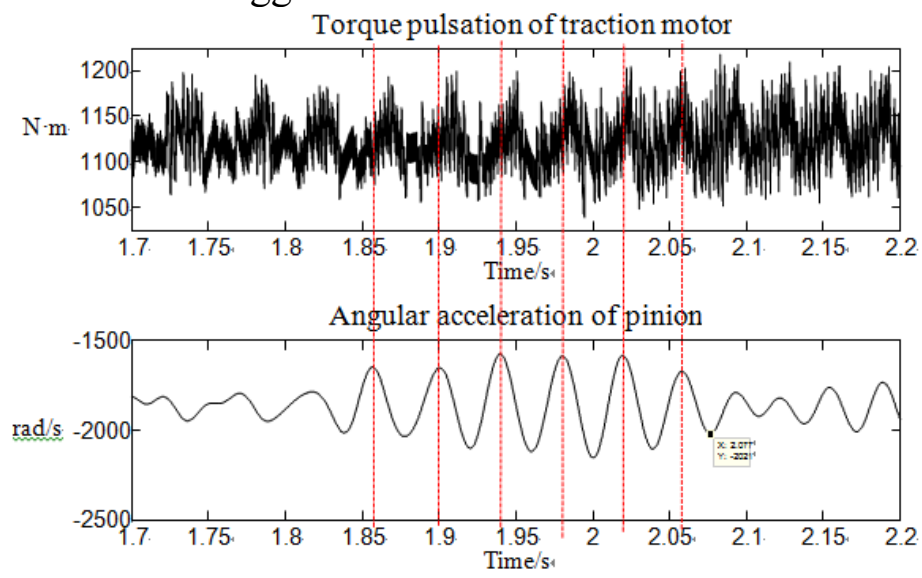

Fig.11. Partial enlarged views of torque pulsation and shaft torsional vibration 
From the above figure, it can be calculated that the torque ripple frequency in the 2 seconds is $151 \mathrm{rad} / \mathrm{s}$, which is the same with resonant frequency $\omega_{3}(24.04 \mathrm{~Hz})$ of drive system in Tab1.

So shaft torsional vibration between traction motor and bogie is serious when the torque ripple frequency is close to natural vibration frequency of drive devices, which will affect the life of device and operation security of train.

\section{Conclusion}

In high-speed train, the low frequency harmonic torque and electromechanical coupled vibration in traction drive system have been studied theoretically as well as simulation, and we can get the following conclusions:

(1) Nonlinear factors of inverter could result in obvious low frequency components in traction motor torque, especially for dead-time effect, which produces 5th, 7 th current harmonics and 6 th pulse harmonic torque.

(2) The natural vibration state has been researched by the model of drive system, and there are three lower natural vibration frequencies when considering system damping: $11.54 \mathrm{~Hz}, 24.04 \mathrm{~Hz}$ and $37.10 \mathrm{~Hz}$.

(3) The drive system can be coupling vibrated obviously when output torque contains natural frequencies above at certain speeds, and there are two resonance speeds of train.

\section{References}

[1] Winterling M W, Tuinman E, Deleroi W. Attenuation of ripple torques in inverter supplied traction drives. [C]. Power Electronics and Variable Speed Drives, 1998. Seventh International Conference on (Conf. Publ. No. 456). IET, 1998: 364-369.

[2] Winterling M W, Tuinman E, Deleroi W. Fault analysis of electromechanical traction drives. [J]. 1997.

[3] Winterling M W, Tuinman E, Deleroi W. Simulation of drive line dynamics of light-rail vehicles. [J]. 1998.

[4] Yao yuan, Zhang hong-jun, Luo yun, Li qiu-ze. Analysis on the Torsional Vibration of Cardan Shaft on CRH5 Motor Car. [J]. China Railway Science, 2009, 30(2):82-86.

[5] Wu mao-gang and so on. Analysis of Torque Ripples of Vector-Controlled Permanent Magnet Synchronous Motors. [J] .Transactions of China Electrotechnical Society,2007,22(2):9-14.

[6] Lipo, T.A, Krause, P.C, Jordan, Howard E. Harmonic Torque and Speed Pulsations in a Rectifier-Inverter Induction Motor Drive. [J]. Power Apparatus and Systems, IEEE Transactions on, 1969, vol.PAS-88, no.5:579-587.

[7] Zhao huai-gen. Research on Dynamics of Locomotive Driving System with Wheelset Quill Shaft and Bogie-mounted Motor. [D]. Southwest Jiaotong University, 2010.

[8] Gu yi-jiong. Safety Analysis and Application on Torsional Vibration of Turbo-Generator Set.

[M]. Science Press, 2013. 